\title{
FUNGAL METABOLISM OF GERTAIN AROMATIC COMPOUNDS RELATED TO LIGNIN
}

\author{
Moira E. K. Henderson \\ Department of Microbiology, The Macaulay Institute for Soil Research, \\ Aberdeen, U.K.
}

\section{INTRODUCTION}

Lignirı is an important natural product which is found in plants of the Pteridophyta and Spermatophyta and which can be one of the main constituents of the plant. According to Erdtman ${ }^{1}$ it amounts to 25-30 per cent of spruce wood. It is produced in several of the plant's tissues where it impregnates the cellulose fibres in cell walls to render the tissue woody. In addition to conferring rigidity on the plant, it protects the cellulose against chemical and physical attack. Since a large amount of plant material finds its way into soil, the fate of the various fractions of it is an important factor in the maintenance of soil structure and fertility. The general picture of decomposition of plant material in soil is that the initial attack is on hemicelluloses and celluloses, with a relative accumulation of lignin, which probably becornes incorporated in the humic acid fraction of soil. The mechanism of lignin decomposition in nature is largely unknown and, until recently, had not been studied in detail, and it was in an attempt to gain some knowledge of this process that the studies to be described were undertaken.

\section{Composition and structure of lignin}

The structure of lignin is still unknown, partly because the bulk of it carnot be isolated unchanged from other plant constituents. A very small fraction, "native lignin", 2 is dissolved by alcohol and is considered to be unchanged lignin, but it may not be representative of all the lignin in a plant. A.ttack on wood by a brown-rot fungus, i.e. one which decomposes cellulose: doubled the yield of native lignin ${ }^{3}$, indicating that cellulose and lignin are closely linked, but it is still not known how. They may be present as a mixture or they may be combined, but evidence seems to favour a chemical combination. Drastic treatments with acid or alkali give larger yields but the products are all considerably altered in the process of isolation.

Present-day knowledge of the chemical composition and structure of lignin is briefly as follows: it consists only of carbon, hydrogen and oxygen, the carbon content being higher than it is in carbohydrates, and the presence of certain groups, such as methoxyl and hydroxyl, has been demonstrated. An aromatic structure is indicated by the release of vanillin on the oxidation of softwood lignins by nitrobenzene under alkaline conditions. Hardwood lignins yield syringaldehyde and vanillin and monocotyledon lignins yield, in addition to these, $p$-hydroxybenzaldehyde ${ }^{5}$. There is also evidence of a side chain of three carbon atoms being attached to some of the aromatic 
rings ${ }^{6}$. The generally accepted theory, based on this information, is that lignin is built up of phenylpropane units, having methoxyl and hydroxyl groups attached to them. The nature of the linkage between the units is not yet known. They may, according to Freudenberg ${ }^{7}$, condense and form benzofuran and benzopyran rings which are linked in chains, or they may be linked in chains with carbon-carbon and carbon-oxygen-carbon linkages ${ }^{1}$.

\section{Lignin in soil}

Since, at the Macaulay Institute, lignin is of prime concern as a constituent of soil organic matter, its manner of occurrence in soil is also of importance. Again this is a matter of conjecture. Various features indicative of the presence of lignin, e.g. methoxyl groups, aromatic ring structures, etc., have been noted in humic acid. According to Gottlieb and Hendricks ${ }^{8}$ the kind and position of the peripheral groupings on the ring are greatly altered. Morrison ${ }^{9,10}$ has studied the aromatic products obtained on oxidation of organic matter derived from soils and peats and has identified $p$-hydroxybenzaldehyde, syringaldehyde and vanillin, and their corresponding acids. However, the proportion of carbon in peats and soils which can be recovered as aromatic compounds is low, being about 5 per cent for peat and usually less than 1 per cent for soil. This does indicate that a fraction of soil organic matter is derived from lignin, but it is not known how much the lignin may have been altered and yet still be able to yield the aldehydes and acids. There is also disagreement over whether or not lignin may become linked with protein to form a resistant complex.

\section{Decomposition of lignin}

(a) Measured by total analysis

This summary will perhaps give some indication of the difficulties which one encounters in trying to study lignin decomposition, pure material being unavailable and the nature of the substance being, to a great extent, unknown. In the past, lignin decomposition has been followed by analysing the changes occurring in plant materials undergoing decay ${ }^{4}$. The results generally showed a fairly rapid disappearance of cellulose, hemicelluloses, etc., and a relative accumulation of lignin whose decomposition proceeds very slowly. Estimation of lignin in soil is difficult but methoxyl content and solubility in 72 per cent $\mathrm{H}_{2} \mathrm{SO}_{4}$ are used as criteria and these also show a proportional increase in lignin content as decomposition of plant material proceeds. However, it is obvious that lignin decomposition must be taking place, otherwise it would be found in soil in quantities much in excess of those which do occur.

\section{(b) By wood-rotting fungi}

Several workers have claimed that fungi, particularly basidiomycetes, can. decompose lignin. Wood-rotting fungi have been divided into "brown-rots" which attack only the cellulose of wood, leaving a brown residue, and "whiterots" which attack lignin, and sometimes cellulose also, leaving a white residue $^{11}$. Using the thioglycolic acid method of estimation, Lindeberg ${ }^{12}$ showed that several basidiomycetes were decomposing the lignin in pine 


\section{METABOLISM OF AROMATIC COMPOUNDS}

needles and beech leaves. Campbell13, 14 demonstrated decomposition of lignin in different woods, again by basidiomycetes, as also did Fahraeus, Nilsson and Nilsson ${ }^{15}$.

\section{(c) Using isolated lignins}

A variety of isolated lignins has been used as growth substrates for fungi and bacteria, but the majority of them are very resistant to biological attack. It must be remembered that such lignins may be altered considerably during the process of extraction and also that they may contain, as impurities, substances which can support growth of micro-organisms, while the lignin itself is not being altered. Native lignin would appear to be the most suitable material for study and several workers have recently succeeded in identifying decomposition products following incubation with white-rot fungi. Ishikawa, Schubert and Nord ${ }^{16}$ identified coniferaldehyde, $p$-hydroxycinnamaldehyde, ferulic acid, 4-hydroxy-3-methoxy-phenylpyruvic acid, $p$-hydroxycinnamic acid, guaiacyl glycerol and its $\beta$-coniferyl ether in culture filtrates. Fukuzumi ${ }^{17}$ also identified the phenylpyruvic acid in a culture filtrate. The former workers also identified vanillin, vanillic acid and dehydrodivanillin. This is a link with earlier work ${ }^{18}$ when vanillin, vanillic acid, syringaldehyde and syringic acid were found to be in some way liberated from lignin in sawdusts attacked by the white-rot fungi Polystictus. versicolor and Trametes pini. The aromatic compounds were not soluble in water or alcohol but could be extracted with alkali from the sawdusts, in amounts which were, in the case of the acids, markedly in excess of those obtained from sawdust which had not been exposed to fungal decay.

\section{(d) Using model compounds}

In wors with lignin model compounds ${ }^{19}$ evidence was obtained of the ability of $P$. versicolor to decompose $\alpha$-guaiacyl-glycol- $\beta$-guaiacyl ether and $\alpha$-guaiacyl-glycerol- $\beta$-guaiacyl ether. A similar compound, $\alpha$-conidendrin, which has been isolated from spruce wood and which consists of two guaiacylproprane units, can be attacked by Flavobacterium sp. ${ }^{20}$, Pseudomonas sp. ${ }^{21}$ and the unidentified bacteria of Sundman ${ }^{22}$. These authors have identified vanillic and iso-vanillic acids as decomposition products.

\section{ME'TABOLISM OF LIGNIN-RELATED AROMATIC COMPOUNDS}

Certain aspects of the metabolism of aromatic compounds have been investigated using bacteria, but little work has been done with fungi. The work to be described has been concerned primarily with different aspects of the metabolism, by soil micro-fungi and by certain wood-rotting basidiomycetes, of the simpler aromatic compounds which, as mentioned above, are related to lignin, and some of which have been shown to be released by biological attack on lignins or lignin-containing materials.

\section{Soil fungi}

\section{(a) Isolation}

On average, fungal propagules of one kind or another are present in soil at the rate of approximately $10^{5}$ per $g$ (dry wt.) soil. A variety of techniques has been cleveloped for isolating the fungi but none is completely satisfactory. 


\section{MOIRA E. K. HENDERSON}

Each one will isolate only a limited number of the total fungal population, and certain types of fungi, such as those which grow only very slowly, or which have very selective growth requirements, cannot survive in competition with more rapidly growing forms in plate culture, or on artificial media. In addition to the general methods for isolation, selective enrichment techniques can be used. In these, the growth of fungi which will attack particular substrates is encouraged by incubating soil or a soil suspension in the presence of the substrate. Fungi which can utilize the substrate will multiply and can then be isolated and cultured. Using a combination of techniques, a considerable number of fungi which can grow on aromatic compounds related to lignin have now been isolated. An attempt was made to make the routine dilution-plate technique selective by incorporating tannic acid in the agar medium and isolating fungi which turned the acid brown ${ }^{23}$. Such a reaction is considered by some to be indicative of an ability to decompose lignin 24 , but little or no correlation was found between the ability to colour tannic acid and to decompose aromatic compounds. Also, soil was incubated in the presence of solutions of aromatic compounds ${ }^{25}$, or of solid material in the form of pellets, and selective development of fungi which can utilize these compounds was thereby obtained.

By employing different fungal isolates according to their suitability for use with different techniques, a considerable amount of information on the metabolism of aromatic compounds has now been gained. In a study of this nature, purely biological techniques are of limited value and a combination of biological and chemical methods (particularly paper chromatographic and spectrochemical) has been used, which has been invaluable in following the decomposition of aromatic compounds and in identifying intermediate products of metabolism.

\section{(b) Growth experiments}

Growth experiments, in which the aromatic compounds were present in a mineral salts medium as sole source of carbon, revealed that many soil fungi could utilize $p$-hydroxybenzaldehyde, ferulic acid, syringaldehyde and vanillin ${ }^{23}$. This indicated that these compounds were being decomposed and further experiments were carried out to study the metabolic pathways involved. Certain intermediate products of metabolism could be identified by ultraviolet analysis of the culture solutions, but growth experiments were generally not suitable for following intermediate metabolism, since the substrates could be used only at very low concentrations. The experimental conditions were altered to resemble those of the well-tried resting-cell technique used for bacteria in which the organisms are first grown on a rich nutrient medium, the resulting growth is washed with water and is then incubated with solutions of the substrates under investigation. In this way one can use higher concentrations of substrates than is possible in growth experiments; also intermediate metabolic products are more likely to accumulate in detectable amounts following the addition of a large quantity of the organism to the substrate solution.

\section{(c) Experiments using pre-grown mycelial mats}

The technique developed by Kluyver and van Zijp ${ }^{26}$, in which fungi are 


\section{METABOLISM OF AROMATIC COMPOUNDS}

grown on liquid medium in stationary flasks, was used. Mycelial mats develop on the surface of the growth medium which is decanted at the end of the growth period, the mats are washed with sterile water and substrate solutions are added. After suitable incubation times these solutions are remioved, acidified, extracted with ether and the extracts examined by paper chromatography. In this way metabolic pathways were determired ${ }^{23,27}$ and several salient features could be picked out as follows:

(i) aldehydes, e.g. p-hydroxybenzaldehyde, syringaldehyde and vanillin are first coxidized to the corresponding acids (Figure 1);

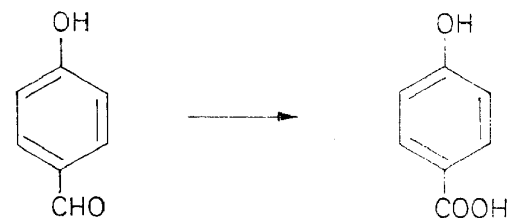

p-Hydroxybenzaldehyde $\quad p$-Hydroxybenzoic acid<smiles>COc1cc(C=O)cc(OC)c1O</smiles>

Syringaldehyde

Syringic acid

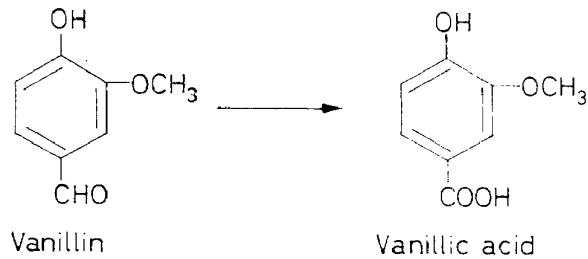

Figure 1. Oxidation of aldehydes to corresponding acids

(ii) additional hydroxyl groups are added to the ring, e.g. $m$-hydroxy and $p$-hydroxybenzoic acids $\rightarrow$ protocatechuic acid, o-hydroxybenzoic acid $\rightarrow$ gentisic acid, benzoic acid $\rightarrow p$-hydroxybenzoic acid (Figure 2);

(iii) methoxyl groups are converted to hydroxyl groups, e.g. o-, $m$ - and $p$-methoxybenzoic acids $\rightarrow 0-, m$ - and p-hydroxybenzoic acids, veratric $\rightarrow$ vanillic acid (Figure 3);

(iv) oxidation of the side chain, e.g. ferulic acid $\rightarrow$ vanillic acid (Figure 3). 


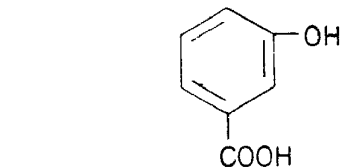

$m$ - Hydroxybenzoic acid<smiles>O=C(O)c1ccc(O)cc1</smiles><smiles>O=C(O)c1ccc(O)c(O)c1</smiles>

Protocatechuic acid

p - Hydroxybenzoic acid

임<smiles>O=C(O)c1ccccc1O</smiles>

o-Hydroxybenzoic acid

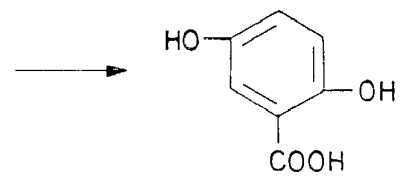

Gentisic acid

$p$-Hydroxybenzoic acid

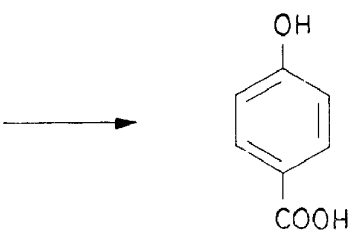

Benzoic acid

Figure 2. Addition of hydroxyl groups to ring

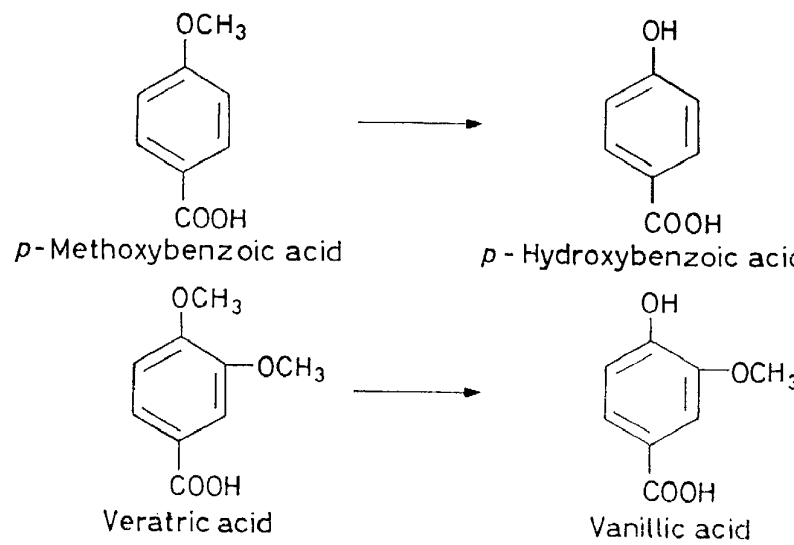

(a) Conversion of methoxyl to hydroxyl groups
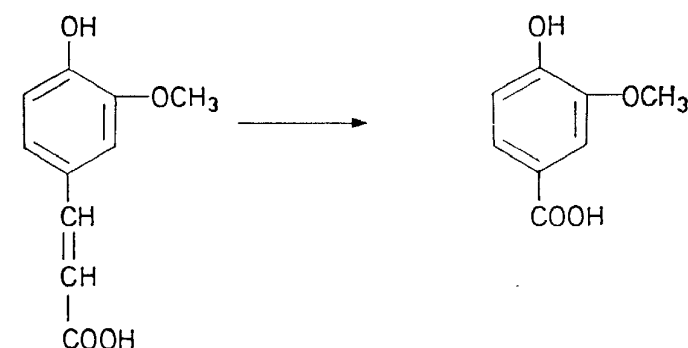

Ferulic acid

Vanillic acid

(b) Oxidation of side chain 


\section{METABOLISM OF AROMATIC COMPOUNDS}

\section{(d) Use of trace element-deficient mycelium}

Certain metals in trace amounts are required for enzyme activity and, by growing fungi in the absence of these metals, the synthesis of some enzymes by the fungi may be markedly reduced or eliminated. The substrates of these enzymes consequently accumulate in the culture solution. Under normal growth conditions requirements for trace elements by fungi, measured in terms of micrograms per litre, are satisfied by contaminating metals in the various constituents of the medium. It is only by very careful removal of such metals that it is possible to obtain fungal growth deficient in them. The activity of such growth is compared with that of mycelium whose trace element requirements are satisfied. A series of experiments using mycelia of Aspergilius niger, Hormodendrum sp. and Penicillium sp. ${ }^{28}$ which were deficient in copper, iron, manganese or zinc, revealed that iron-deficient mycelium took considerably longer to metabolize the compounds than did nondeficient mycelium, while intermediate products of metabolism accumulated in larger amounts. The intermediates which accumulated were catechol, formed from $o$-hydroxybenzoic acid and protocatechuic acid formed from $m$ - and $b$-hydroxybenzoic acid. The metabolism of aromatic compounds by copper-, manganese- and zinc-deficient cultures was unaffected and it is assumed that these metals were not involved in the metabolism of such compounds. Iron had previously been shown to play a part in the activity of protccatechuic acid oxidase from Pseudomonas sp. ${ }^{29}$, while pyrocatechase, also from Pseudomonas sp., had been shown to contain two atoms of iron per molecule of protein ${ }^{30}$.

\section{(e) Adajtation}

While some substrates are metabolized immediately by micro-organisms, others are utilized only after a lag period, during which time the organism synthesizes the enzymes necessary for metabolism and becomes adapted to the substrate ${ }^{31}$. Growth on, or previous exposure to, the substrate eliminates the lag period. Adapted cells immediately metabolize not only the initial substrate but also the successive intermediates arising from it. Thus if a substrate $\mathrm{A}$ is metabolized to form, in succession, intermediates $\mathrm{B}, \mathrm{C}$ and $\mathrm{D}$, then cells which have been adapted to $\mathrm{A}$ will probably also be adapted to B, G arid D. Evidence for the occurrence of a suspected metabolite (D), which is metabolized only after a lag period, in a particular metabolic pathway, can therefore be obtained by adapting the organism to the initial substrate $(A)$ by growing it on, or in the presence of, $A$ and then ascertaining if it will metabolize $\mathrm{D}$ without a lag period. If it does so this indicates that $\mathrm{D}$ is probably formed during the metabolism of A. This principle was used as a basis for several techniques in work with fungi.

In respiration experiments in the Warburg apparatus, where oxygen uptake was taken as the criterion for metabolic rate, very young mycelial material in the form of newly germinated spores was used ${ }^{32}$. Mycelium which had been exposed to $p$-hydroxybenzaldehyde was adapted to $p$ hydroxybenzoic acid, while exposure to ferulic acid or vanillin led to adaptation to vanillic acid and exposure to syringaldehyde adapted the mycelium to syringic acid. In this type of experiment adapted mycelia show an increased rate of oxygen uptake soon after addition of the substrate, while 
with non-adapted mycelia there is a considerable lag period before this occurs (Figure 4).

A fungus which was isolated by means of an enrichment technique is Pullularia pullulans ${ }^{33}$. This fungus grows in a yeast-like form on liquid medium in shake culture and in such a form it is more suitable for use in several techniques than are fungi which grow only in a mycelial form. Intact cells were used for respiration experiments and these were adapted by incubating

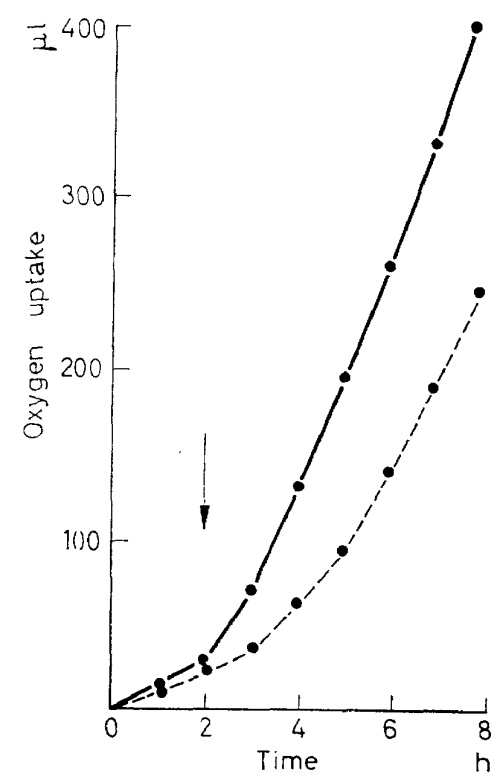

Figure 4. Oxygen uptakes by adapted and non-adapted mycelium; substrate added at point indicated by arrow: adapted mycelium - . - non-adapted mycelium

overnight in solutions of substrate. On subsequent addition of intermediate metabolic products an increased rate of oxygen uptake occurred without an intervening lag period ${ }^{34}$. In this wáy it was found that previous incubation with vanillin, vanillic acid, $p$-hydroxybenzaldehyde or $p$-hydroxybenzoic acid led to adaptation to protocatechuic acid, while incubation with syringic acid did not do so.

$P$. pullulans was used to carry the metabolic pathway further. From the yeast-like growth cell-free extracts could be prepared which showed ability to oxidize protocatechuic acid, if the cells had previously been exposed to this acid or to a precursor of $\mathrm{it}^{34}$. Some activity was present in non-adapted cells but it was very low. Further steps in metabolic pathways indicated by these results are summarized in Figure 5. It was found that exposure to $m$ and $p$-hydroxybenzoic acids and to vanillic acid caused adaptation to protocatechuic acid. While exposure to $o$-hydroxybenzoic acid and catechol did not adapt cells to protocatechuic acid, it did adapt them to catechol and to cis-cis-muconic acid. Metabolism of protocatechuic acid, catechol and cis-cis-muconic acid all led to the production of $\beta$-ketoadipic acid which 


\section{METABOLISM OF AROMATIC COMPOUNDS}

accumulated and which was measured by decarboxylation. Of course there are: several intermediates between protocatechuic and cis-cis-muconic acids and $\beta$-ketoadipic acid. One significant feature of the results obtained by this method is that two of the lignin-related molecules, i.e. vanillic and $p$ hydroxyijenzoic acids, were linked with protocatechuic acid, which is a key intermecliate in metabolism of aromatic compounds.<smiles>O=C(O)c1cccc(O)c1</smiles>

$m$ - Hydroxybenzoic acid

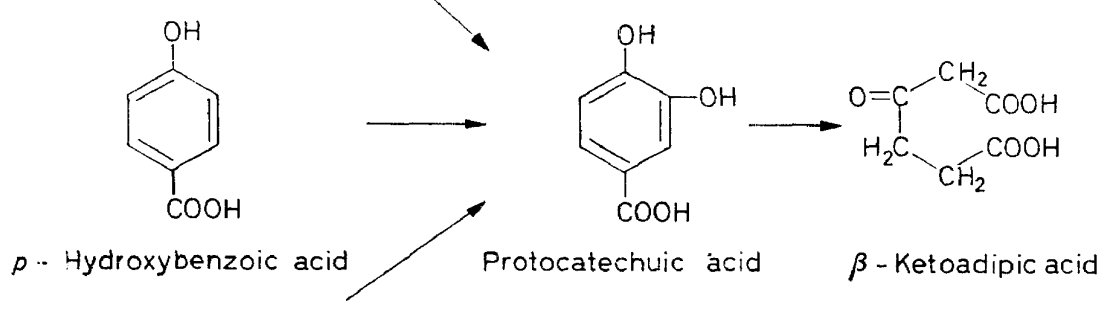<smiles>COc1cc(C(=O)O)ccc1O</smiles>

Vanillic acid<smiles>O=C(O)c1ccccc1O</smiles><smiles>Oc1ccccc1O</smiles><smiles>O=C(O)/C=C\C=C/C(=O)O</smiles>

o- Hydroxybenzoic acid

Catechol<smiles>CC(C)C(=O)OCCCC(=O)CC(=O)O</smiles>

Figure 5. Metabolic steps identified by use of $P$. pullulans cell extracts

The general picture of the metabolism of aromatic compounds by the soil micro-furgi studied would appear to be one of successive oxidative or demethoxylative steps leading to the production of protocatechuic acid, after which the aromatic structure disappears and aliphatic compounds are formed. From some of the fungi $\beta$-ketoadipic acid could be identified as the next product and, with its appearance, the fungal pathways have merged with those which have been well worked out for bacteria, i.e. passing through cis-cis $\beta$-carboxymuconic acid. At this stage in the investigation it would have been necessary to enter the field of enzymology, which was not attempted. A considerable amount has, however, been done by other workers with bacterial enzymes and, at present, it seems that there may be several distinct pathways for the final stages of the process. Little has been 


\section{MOIRA E. K. HENDERSON}

done with fungi, apart from Neurospora crassa ${ }^{35}$, which has been found to resemble strains of Pseudomonas, Vibrio and Nocardia ${ }^{36}$ in forming cis-cis $\beta$ carboxymuconic acid from protocatechuic acid as a result of splitting the ring between the two hydroxyl groups, the enzyme involved being protocatechuic acid oxidase (Figure 6). Carboxymuconic acid may then be converted to $\beta$-carboxymuconolactone or decarboxylated to $(+)$ - muconolactone $\mathrm{e}^{37}$. In the latter case lactonization and decarboxylation appear to

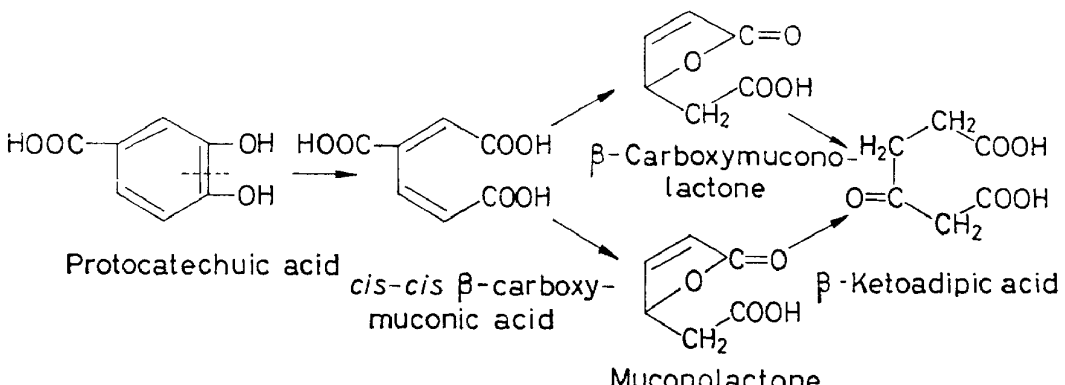

(a) Splitting of ring in 3:4 position

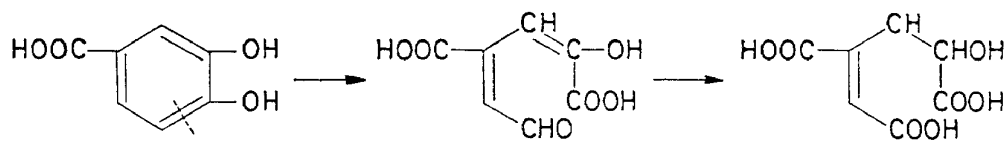

Protocatechuic acid $\quad \alpha$-Hydroxy- $\nu$-carboxy- $\quad 2$-Hydroxy-4-carboxymuconic semialdehyde 2:3-dihydromuconate

(b) Splitting of ring in 4:5 position

Figure 6

occur simultaneously. $\beta$-Carboxymuconolactone or $(+)$-muconolactone are then converted to $\beta$-ketoadipic acid which is decomposed and its products subsequently enter the tricarboxylic acid cycle ${ }^{38,39}$.

Protocatechuic acid may also be split by Pseudomonas sp. in the $4: 5$ position to yield $\alpha$-hydroxy- $\gamma$-carboxymuconic semialdehyde, which undergoes an internal oxidation reduction to yield 2-hydroxy-4-carboxy-2:3-dihydromuconate $^{36}$ (Figure 6).

\section{Wood-rotting fungi}

As indicated in the introduction, a number of workers has used the wood-rotting basidiomycetes in studies on lignin decomposition and the results obtained indicated that such fungi could decompose lignin, and some of the decomposition products have been isolated ${ }^{16-18}$. A series of experiments, designed to study the metabolic activity of wood-rotting fungi on the aromatic compounds, revealed a number of points of interest concerning fungal metabolism of aromatic compounds.

\section{(a) Phenoloxidases}

The action of these enzymes is the most noticeable feature since, on 


\section{METABOLISM OF AROMATIC COMPOUNDS}

incubating fungi, which produce phenoloxidases, in the presence of phenols, coloured products are formed. Such activity was, with one or two exceptions, absent from the soil micro-fungi. The formation of the coloured products, thought to be quinones, is most apparent when the phenols are incorpcrated in a solid medium. Then a distinct zone, varying in colour according to the phenol, is formed beneath the fungal colony. In some cases growth may be inhibited but the enzyme may diffuse out from the inoculum to produce a coloured halo. Phenoloxidase activity is usually greatest in a rich medium. There are two enzymes which have this type of action, laccase (cxidizing di- and polyphenols with two hydroxyl groups in the ortho or para positions) and tyrosinase (oxidizing monophenols, di- and polyphenols with two hydroxyl groups in the ortho position) and some consider that they may be partly responsible for lignin decay, being generally found in fungi which rot wood. $P$. versicolor, which produced phenoloxidase, did not grow on $p$-hydrexybenzaldehyde, ferulic acid, syringaldehyde or vanillin, but the three latter compounds were metabolized through syringic and vanillic acids as with the micro-fungi. When glucose was added to the basal mineral salts medium the amount of conversion of the aromatic materials was greater, probably due to a combination of phenoloxidase activity and of decomposition. Flaig and Haider ${ }^{40}$ found, however, that white rots would grow on such compounds as the sole source of carbon and that protocatechuic acid was formed and was subsequently metabolized through $\beta$-ketoadipic acid.

\section{(b) Reduction of aromatic acids and aldehydes}

When the technique of growing fungal mats and then incubating them over solutions of the phenolic acids was used with $P$. versicolor some acids were reduced to the corresponding aldehydes and alcohols ${ }^{41}$ (Figure 7). m- and $p$-Methoxybenzoic, 3:4-dimethoxybenzoic and $\beta$-naphthoic acids all yielded the corresponding aldehydes and alcohols, but only the alcohols from

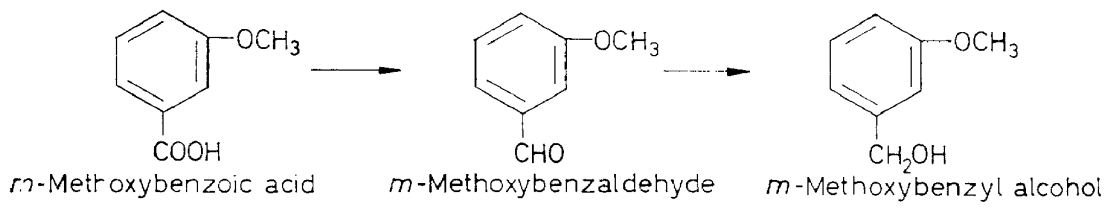

m-Methoxybenzaldehyde

m-Methoxybenzyl alcohoi
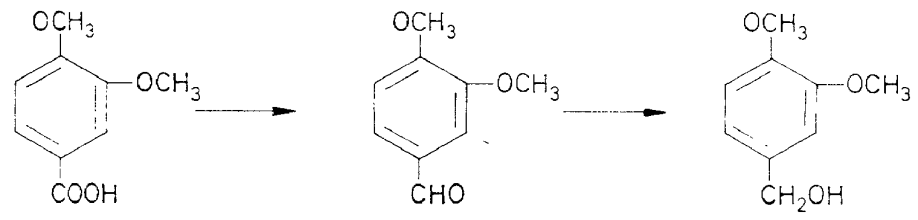

Ve-atric acid

Veratricaldehyde

Veratryl alcohol
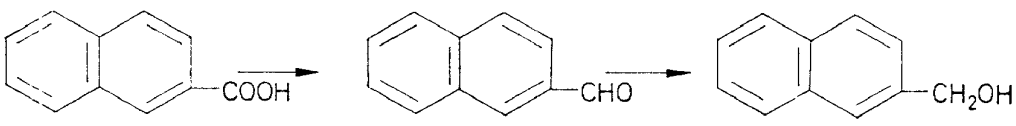

$\beta$ - Napthoic acid

$\beta$ - Naphthaldehyde

B - Naphthyl alcohol

Figure 7. Reduction of acids and aldehydes by $P$, versicolor 
$o$-methoxybenzoic and benzoic acids were detected. Some acids which were tested were not reduced-these were 2:4-dimethoxybenzoic, phenylacetic and $\alpha$-naphthoic. Shimazono and Nord ${ }^{42}$ also found that $P$. versicolor reduced $p$-methoxybenzoic acid to aldehyde and alcohol under aerobic conditions. In addition to the reduction activity, this fungus also possessed some of the activities detected in the micro-fungi, e.g. $o$-, $m$ - and $p$-methoxybenzoic acids were partially demethoxylated to the corresponding hydroxybenzoic acids, while hydroxylation in the para position of cinnamic, benzoic and phenylacetic acids also occurred. During the metabolism of some acids, too, the aromatic structure was partially broken down. These were cinnamic, $\beta$-naphthoic, $o$ - and $p$-hydroxybenzoic acids.

The reductive system might have been favoured by anaerobic conditions in the culture flask. However, aeration, obtained by bubbling air through the flask, did not eliminate reduction of $p$-methoxybenzoic acid while anaerobic conditions, achieved by filling the flask with nitrogen, slowed down the reduction rate considerably. Recently a report has appeared ${ }^{43}$ concerning $^{-}$ the occurrence of a similar reductive activity in Aspergillus niger when incubated with aminobenzoic acids, which were reduced to the corresponding aldehydes 0 - and $p$-Hydroxybenzoic acids were decomposed by this fungus also. Reduction of benzaldehyde to benzyl alcohol took place if anaerobiosis was induced by tightly stoppering the flask.

\section{(c) Aromatic alcohol dehydrogenase}

In the experiments on reduction the concentration of $p$-methoxybenzaldehyde fluctuated erratically. In an aliquot of culture solution removed from a culture of $P$. versicolor on $p$-methoxybenzoic acid and stored for two days, the concentration of aldehyde increased, while the concentration of alcohol fell. This conversion of alcohol to aldehyde could be eliminated by autoclaving the aliquot prior to storage, which suggested that an extracellular enzyme might be involved. An aromatic alcohol dehydrogenase was then found to be present in the culture solutions. It was also produced in the growth medium ${ }^{44}$, which could be used directly as a source of it, or a concentrate could be obtained by saturating the medium with ammonium sulphate and suspending the resulting precipitate in water and dialysing against phosphate buffer. Enzyme activity was estimated spectrochemically by measuring the rate of oxidation of $p$-methoxybenzyl alcohol to $p$-methoxybenzaldehyde. It could also be estimated by measuring oxygen uptake in the Warburg apparatus. The enzyme dehydrogenated the following primary aromatic alcohols: benzyl alcohol and its $p$-methoxy, $m$-methoxy, 3:4dimethoxy, 4-hydroxy-3-methoxy, $o$-hydroxy and $p$-hydroxy derivatives, 4-hydroxy-3-methoxy cinnamyl alcohol, and $\beta$-naphthyl carbinol, but not the secondary aromatic alcohols 1-(3:4-dimethoxyphenyl)ethanol, 1-(4hydroxy-3-methoxyphenyl)ethanol and 1-(4-methoxyphenyl)ethanol. The enzyme may be a flavoprotein but it was not studied in detail.

\section{DISGUSSION}

In trying to solve a complex problem, such as that of lignin decomposition, it is obvious that one cannot approach the problem directly, but must investigate the subject from as many different aspects as possible, making use 


\section{METABOLISM OF AROMATIC COMPOUNDS}

of all the techniques and organisms available. The results obtained must then be considered in relation to the problem as a whole in an attempt to fird the solution.

It is still not possible to explain how lignin decomposition may occur, but results so far obtained enable the formulation of a possible scheme. Since lignin is an insoluble material it is presumably attacked by extracellular enzymes, with the release of constitutive units. There is now a considerable amount of experimental evidence in favour of this, which has resulted from work with sawdust and with various lignin model compounds which have been subjected to attack by various wood-rotting basidiomycetes. In most cases the released units are aromatic and consist of a single ring structure, with various substituent groups. However, the units are released only in very small amounts. It is not known how they are incorporated in the lignin molecule and their release may be indicative of attack only on side groups atrached to lignin and not on the main lignin structure itself.

These aromatic units can then be metabolized by a variety of soilinhabiting fungi and bacteria 45,46 . Many of the units have methoxyl groups attached to them which are first converted to hydroxyl groups, as has been demonstrated with several of the fungi. The actual mechanism of demethoxylation has not yet been explained. Demethoxylation is an important feature of lignin decomposition under natural conditions where chemical analyses have shown that decomposition is accompanied by a decrease in methoxyl content. In addition to the conversion of methoxyl to hydroxyl groups, additional hydroxyl groups may be added to the ring. A unit with two adjacent hydroxyl groups, such as protocatechuic acid or catechol, is susceptible to ring fission.

A rôle in lignin decomposition has not yet been ascribed to the reducing activity of $P$. versicolor or to its aromatic alcohol dehydrogenase. The enzyme oxidizes primary alcoholic groups only, of which there are probably only very few in lignin. It does not oxidize the secondary aromatic alcohols or the secondary alcoholic groupings in the lignin model compounds. In connection with the ability of $P$. versicolor to reduce aromatic compounds, it is of interest to note that it has recently been suggested that, in the breakdown of humic acid by fungi, the first step is a reductive one in which carboxyl groups are first reduced to aldehyde groups and then to primary alcohol groups ${ }^{47}$.

\section{References}

1 H. Erdiman. Tappi 32, 71 (1949).

2 jF. E. Bauns. J. Am. Chem. Soc. 61, 2120 (1939).

3 W. J. Schubert and F. F. Nord. J. Am. Chem. Soc. 72, 977 (1950).

4 A. G. Norman. The Biochemistry of Cellulose, The Polyuronides, Lignin, etc., Clarendon Press, Oxford (1937).

5 R. H. J. Creighton, R. D. Gibbs, and H. Hibbert. J. Am. Chem. Soc. 66, 32 (1944).

${ }^{6}$ E. E. Harris, J. D'Ianni, and H. Adkins. J. Am. Chem. Soc. 60, 1467 (1938).

7 F'. E. Brauns. The Chemistry of Lignin, Academic Press, New York (1954).

8 s. Gottlieb and S. B. Hendricks. Soil Sci. Soc. Am. Proc. 10, 117 (1946).

R. I. Morrison. J. Soil Sci. 9, 130 (1958).

10 R. I. Morrison. J. Soil Sci. (in press).

11 R. Falck and W. Haag. Ber. Deut. Botan. Ges. 60, 225 (1927).

12 (G. Lindeberg. Symbolae Botan. Upsalienses 8, 1 (1944).

13 W. G. Campbell. Biochem. J. 24, 1235 (1930). 


\section{MOIRA E. K. HENDERSON}

14 W. G. Campbell. Biochem. J. 25, 2023 (1931).

15 G. Fahraeus, R. Nilsson, and G. Nilsson. Botan. Tidsskr. 43, 343 (1949).

16 H. Ishikawa, W. J. Schubert, and F. F. Nord. Arch. Biochem. Biophys. 100, 131 (1963).

17 T. Fukuzumi. Bull. Agr. Chem. Soc. Japan 24, 728 (1960).

18 M. E. K. Henderson. Nature 175, 634 (1955).

${ }^{19}$ J. D. Russell, M. E. K. Henderson, and V. C. Farmer. Biochim. Biophys. Acta 52, 565 (1961).

20 W. A. Konetzka, M. J. Pelczar, and S. Gottlieb. J. Bacteriol. 63, 171 (1952).

21 H. H. Tabak, C. W. Chambers, and P. W. Kabler. J. Bacteriol. 78, 469 (1959).

${ }^{22}$ V. Sundman. Finska Kemistsamfundets Medd. 71, 26 (1962).

${ }^{23}$ M. E. K. Henderson and V. C. Farmer. J. Gen. Microbiol. 12, 37 (1955).

24 W. Bavendamn. Pflanzenkrankh. Pflanzenschutz. 38, 257 (1928).

25 M. E. K. Henderson. J. Gen. Microbiol. 26, 149 (1961).

${ }^{26}$ A. J. Kluyver and J. C. M. van Zijp. Antonie van Leeuwenhoek J. Microbiol. Serol. 17, 47 (1951).

27 M. E. K. Henderson. J. Gen. Microbiol. 16, 686 (1957).

${ }^{28}$ M. E. K. Henderson. J. Gen. Microbiol. 23, 307 (1960).

29 S. Dagley and M. D. Patel. Biochem. J. 66, 227 (1957).

30 O. Hayaishi, M. Katagiri, and R. Simon. J. Biol. Chem. 229, 905 (1957).

31 R. Y. Stanier. J. Bacteriol. 54, 339 (1947).

32 M. E. K. Henderson. J. Gen. Microbiol. 14, 684 (1956).

${ }^{33}$ M. E. K. Henderson. J. Gen. Microbiol. 26, 149 (1961).

${ }^{34}$ M. E. K. Henderson. J. Gen. Microbiol. 26, 155 (1961).

${ }_{35}$ S. R. Gross, R. D. Gafford, and E. L. Tatum. J. Biol. Chem. 219, 781 (1956).

36 S. Dagley, W. C. Evans, and D. W. Ribbons. Nature 188, 560 (1960).

37 R. B. Cain. Biochem. J. 79, 298 (1961).

${ }^{38}$ M. Katagiri and O. Hayaishi. J. Biol. Chem. 226, 439 (1957).

39 L. J. Ottey and E. L. Tatum. J. Biol. Chem. 229, 77 (1957).

${ }^{40}$ W. Flaig and K. Haider. Arch. Mikrobiol. 40, 212 (1961).

41 V. G. Farmer, M. E. K. Henderson, and J. D. Russell. Biochim. Biophys. Acta 35, 202 (1959).

42 H. Shimazono and F. F. Nord. Arch. Biochem. Biophys. 87, 140 (1960).

43 T. S. Raman and E. R. B. Shanmugasundaram. J. Bacteriol. 84, 1339 (1962).

44 V. G. Farmer, M. E. K. Henderson, and J. D. Russell. Biochem. J. 74, 257 (1960).

45 R. Moreau and J. Augier. Compt. Rend. 254, 555 (1962).

16 W. J. Robbins and A. B. Massey. Soil Sci. 10, $237(1920)$.

47 H. M. Hurst, A. Burges, and P. Latter. Phytochemistry 1, 227 (1962). 